\title{
DO ESTUDO ACADÊMICO DA BÍBLIA HEBRAICA
}

\author{
Suzana Chwarts*
}

Resumo: Este artigo apresenta uma retrospectiva sintetizada da trajetória dos estudos acadêmicos da Bíblia Hebraica, ressaltando a heterogeneidade das abordagens empregadas no processo de compreensão e interpretação do relato bíblico.

Palavras-chave: Metodologia, Bíblia Hebraica, Estudos Bíblicos .

Resume: This article presents a synthesis of the trajectory of the academic studies of the Hebrew Bible, focusing on the heterogeneity of the approaches employed in the process of comprehension and interpretation of the Biblical account.

Keywords: Methodology, Hebrew Bible, Biblical Studies.

Muitos estudiosos atuais ${ }^{1}$ consideram Benedict Spinoza, filósofo judeu do século 17, o fundador da abordagem científica à Bíblia Hebraica, com base em seu Tratado Teológico-Político, publicado em 1670. Neste o autor argumenta que a Bíblia Hebraica deveria ser objeto de estudo científico e formula uma linha metodológica para seu estudo, fundamentada no exercício crítico da razão e da história.

As conclusões de Spinoza sobre Deus levaram a sua excomunhão e os estudos acadêmicos da Bíblia Hebraica permaneceram engessados na teologia judaica e cristã, até seu renascimento no círculo protestante do século 19, na Alemanha.

Inspirados pela crítica histórica, que já havia sido aplicada aos textos clássicos durante a Renascença, e influenciados por correntes intelectuais de seu tempo - como o romantismo e a teoria da evolução - os estudiosos alemães romperam definitivamente com a teologia, submetendo o texto bíblico à investigação filológica da mesma forma que um texto secular, e desconsiderando todas as tradições relacionadas à autoria e autoridade.

\footnotetext{
* Professora Doutora de Estudos da Bíblia Hebraica na Faculdade de Filosofia, Letras e Ciências Humanas. 1. Sarna, Naum M.. Understanding Genesis. The World of the Bible in the Light of History. New York: Schocken Books, 1966, p. xxi.
} 
O principal pilar da discussão teológica - o conceito de verdade - foi descartado para abrir espaço à investigação crítica, livre dos pressupostos da religião e da tradição exegética.

Se, por um lado, pesquisadores como Wellhausen empreenderam um estudo minucioso e erudito, por outro, chegaram a conclusões que refletiram apenas a bias do final do século 19: sua idealização da religião imaculada de Israel era profundamente romântica e sua caracterização do judaísmo pós-exílico como sistema meramente legalista e declinante era profundamente anti-semita.

A sua Hipótese Documental, entretanto, tornou-se uma afirmação clássica, uma teoria que estudiosos posteriores desenvolveram, aceitaram ou rejeitaram, de uma forma ou de outra, sempre dialogando com ela. A idéia da combinação de diferentes fontes, de períodos diversos, no desenvolvimento do que hoje conhecemos como Pentateuco tornou-se um pressuposto amplamente aceito entre estudiosos da Bíblia Hebraica.

Um evento no mundo da arqueologia mudaria para sempre o curso dos estudos da Bíblia Hebraica: as descobertas dos arquivos reais e bibliotecas de cidades mesopotâmicas, canaanéias e egípcias e seus tesouros epigráficos revelaram aos estudiosos modernos o fato, até então desconhecido, de que o antigo Oriente Médio formava um continuum cultural, com intensa troca de influências numa extensa área que incluía a Mesopotâmia, a Síria, Canaã, a costa da Ásia Menor, Chipre, Creta e Egito.

A descoberta dos escritos do antigo Oriente Médio coincidiu com a emergência de novas disciplinas como a antropologia, a sociologia e o estudo do folclore; e tanto as novas evidências quanto as novas disciplinas foram incorporadas ao estudo acadêmico da Bíblia Hebraica, que passou a ser ministrado nas grandes universidades, inserido em áreas como: estudos da religião, estudos orientais ou semitas e estudos do judaísmo.

Esses documentos permitiram a sincronização com informações contidas no relato bíblico, e as analogias foram empregadas para equacionar a distância e a proximidade entre as culturas, e sobretudo, para restituir o texto a seu contexto original e retirá-lo do vácuo sagrado da exegese.

O influxo de data extrabíblica, juntamente com o estudo da tradição oral e do folclore, criou as bases para um novo tipo de abordagem, que transferiu o foco de interesse do aspecto histórico para o literário. $O$ foco passou a ser a intenção do autor/ redator bíblico, que se manifesta na forma e na organização de seu trabalho em unidades textuais maiores e mais complexas.

A esta abordagem convencionou-se chamar crítica redacional, embora seja parte integrante da crítica histórico-gramatical, e não constitui um método diferenciado. 
Sua preeminência, nos últimos anos, é coerente com o crescente interesse pelo estudo de unidades maiores de texto, que vem banindo, gradativamente, o antigo sistema de análise versículo-por-versículo, prevalecente na tradição teológica e nas primeiras décadas de estudos acadêmicos.

Mas foi a crítica literária que abriu, de fato, uma nova perspectiva para se compreender a Bíblia Hebraica. A aplicação de sua metodologia, apoiada no estudo de filologia semítica comparada, permitiu a apreensão dos recursos expressivos do hebraico bíblico - as nuances dos valores léxicos, a força das metáforas e dos paralelismos, a integridade estilística e rítmica do texto.

A idéia central desta abordagem consiste em considerar o conjunto da Bíblia Hebraica como uma obra literária, e estudá-la tal como ela é, concentrando menor atenção nas circunstâncias históricas de sua composição. O método empregado é o da crítica retórica (close reading), mas o objetivo final é a apreensão do significado do todo, a visão holística e não atomística. Por esta razão, cada vez mais ênfase tem sido colocada no enfoque interdisciplinar no âmbito dos estudos bíblicos.

Este percurso possui a qualidade de criar novos parâmetros de compreensão, além de exigir a movimentação em diversas áreas disciplinares e o confronto entre conceitos e instrumentos teóricos de correntes diversas.

A trajetória interdisciplinar é articulada, no caso da Bíblia Hebraica, a partir dos paradigmas da crítica literária e da crítica histórica que, associados, propõem um eixo de raciocínio fecundo, valioso na elucidação do texto e da visão de mundo que expressa.

Tal é a opinião de grande parte dos estudiosos modernos, como Gotwald ${ }^{2}$, por exemplo, que argumenta ser o eixo comum aos paradigmas a preocupação central com a estrutura: a estrutura dos escritos, por um lado - objeto da crítica literária e a estrutura da sociedade israelita e judaica na qual a Bíblia Hebraica foi escrita e transmitida.

Os textos da Bíblia Hebraica - compostos, alinhavados, editados e reeditados ao longo de nove séculos - formam o corpus literário fundacional da cultura israelita, e são suas palavras e imagens que compõem as tradições autoritativas desta cultura.

No processo de compreensão deste núcleo texto/cultura é necessário reconhecer, e tentar ultrapassar, as limitações de cada método já consagrado nos estudos bíblicos. Isto se dá exatamente através do olhar criativo, renovador, que um outro método oferece.

2. Gotwald, Norman K. Introdução Socioliterária à Bíblia Hebraica (trad. Anacleto Alvarez). São Paulo: Paulus, 1988, p.41. 
Assim, a resposta a uma pergunta sobre o rei Davi - afirma Gotwald ${ }^{3}$ - gravita por canais metodológicos distintos, e transborda. Cada resposta evidencia um aparato - lingüístico, literário, antropológico, arqueológico - empregado com o intuito de iluminar o texto bíblico, através de uma confluência fértil, mas rigorosamente controlada, de modelos. E, no entanto, cada resposta evidencia também novos questionamentos, saturados de subjetividades, de caráter inesperado, o que não permite a inércia nem a observação pré-moldada.

É este caráter da Bíblia Hebraica - o de estar sempre aberta à descoberta e a novas interpretações - que tem suscitado a demanda de abordagens inovadoras para seu estudo.

Entre as mais recentes, destacam-se o feminismo, o liberacionismo e o póscolonialismo (agrupadas sob o termo "guarda-chuva" hermenêutica cultural), nas quais a posição do intérprete não é apenas explicitada e validada, mas serve como princípio normativo no processo de interpretação, centrado nas categorias de classe, etnia e gênero. O estudioso explora ângulos, até então desprezados, deslocando temas do passado para a sua realidade, e articulando-os - passado e presente - de tal maneira que ambos são transformados. A Bíblia se impõe como texto de liberação, principalmente a narrativa do êxodo e os escritos dos profetas, núcleo irradiador desses movimentos revolucionários.

Também o fluxo contínuo de informações impulsionou os estudos bíblicos a incorporar novas abordagens. Desde 1970, a arqueologia tem revelado cada vez mais data sobre a configuração da população, costumes domésticos e religiosos, práticas agrícolas, pecuaristas e comerciais do mundo bíblico. O material epigráfico, descoberto em escavações e datado com precisão, constitui uma evidência valiosa para a contextualização dos escritos bíblicos.

Essas informações, juntamente com um amplo leque de possibilidades de modelos comparativos de sociedades não urbanas descentralizadas, têm gerado novas hipóteses sobre os primórdios de Israel, sem que nenhum consenso tenha sido ainda alcançado.

É através deste "caleidoscópio multimetodológico" que a Bíblia Hebraica emerge como um documento essencialmente humano, que registra o anseio do homem para compreender Deus nas relações humanas e na história de um povo.

Por esta razão, embora essencialmente secular, o estudo acadêmico não deve dessacralizar a Bíblia Hebraica. Não se pode exilar o elemento sagrado de escritos que foram formulados com o propósito explícito de ser literatura sagrada, nem

3. idem, p. 41. 
desconsiderar os significados de revelação, punição e redenção atribuídos a eventos da história dos antigos israelitas.

A sobrevivência dos livros que compõem a Bíblia Hebraica deve-se à crença por parte dos israelitas de que ela continha a palavra de Deus e palavras inspiradas por Deus. Embora não se empregue uma hermenêutica específica para tratar de textos consagrados pela tradição como sagrados, qualquer outra postura, que não a de respeitar esta dimensão dos textos bíblicos, implica perverter a sua essência.

O desafio do estudo acadêmico da Bíblia Hebraica, contudo, não se restringe à abordagem crítica. Os modos de expressão, categorias de pensamento e o ambiente sociocultural pressupostos nas narrativas e nas leis são estranhos ao pensamento ocidental, embora o Antigo Testamento seja o livro mais lido do mundo.

$\mathrm{O}$ contato da grande massa de leitores, e surpreendentemente de vários estudiosos, com a Bíblia Hebraica dá-se através de suas inúmeras apropriações: traduções, versões, paráfrases antigas e modernas. Já o texto hebraico suscita uma compreensão totalmente distinta, em particular por sua raiz triconsonantal que permite múltiplas significações, entrelaçando sentidos e construindo um texto fértil em polissemias e ambigüidades, um desafio a qualquer exercício de tradução.

Debruçar-se, horas a fio, sobre o original, implica reformular nosso padrão de pensamento e raciocínio, e mergulhar nas dimensões de uma racionalidade antiga e desconhecida, que se revela aos poucos, encantando-nos no processo de sua leitura interminável.

\section{Bibliografia:}

Gotwald, Norman K. Introdução Socioliterária à Bíblia Hebraica (trad. Anacleto Alvarez) São Paulo: Paulus, 1988.

Sarna, Naum M. Understanding Genesis.The World of the Bible in the Light of History. New York: Schocken Books, 1966. 